\title{
From cellular senescence to regeneration: A quest for the holy grail for the next generation of surgeons?
}

\author{
Igor E. Konstantinov, MD, PhD, FRACS, Xin Tao Ye, MD, and Tyson A. Fricke, MBBS, BMedSci
}

\footnotetext{
From the Department of Cardiothoracic Surgery, The Royal Children's Hospital, The University of Melbourne and the Murdoch Children's Research Institute, Melbourne, Victoria, Australia. Disclosures: Authors have nothing to disclose with regard to commercial support.

Received for publication April 28, 2017; accepted for publication May 11, 2017; available ahead of print June 20, 2017.

Address for reprints: Igor E. Konstantinov, MD, PhD, FRACS, The Royal Children's Hospital, Flemington Rd, Parkville, Melbourne, Victoria 3029, Australia (E-mail: igor.konstantinov@rch.org.au).

J Thorac Cardiovasc Surg 2017;154:953-4

$0022-5223 / \$ 36.00$

Crown Copyright (c) 2017 Published by Elsevier Inc. on behalf of The American Association for Thoracic Surgery http://dx.doi.org/10.1016/j.jtcvs.2017.05.036
}

In 2006, Harriet, 1 of 3 tortoises believed to be taken from the Galapagos Islands by Charles Darwin on his historic 1835 voyage aboard the HMS Beagle, died of heart failure in an Australian zoo. She was 176 years old. Although this fascinating fact may have passed unnoticed by most cardiothoracic surgeons, it may have a subtle yet direct relevance to the broader aspects of tissue regeneration. In 1961, Leonard Hayflick and Paul Moorhead discovered that human embryonic-derived cells could divide only a limited number of times and stopped dividing after an average of 50 cycles. ${ }^{1}$ In comparison, cells from the Galapagos tortoise divided approximately 110 times, whereas mouse cells divided about 15 times. This phenomenon is known today as the Hayflick limit, or replicative senescence.

The potential clinical significance of such cellular senescence is exemplified in a thorough and insightful study published in this issue of the Journal by Han and colleagues. ${ }^{2}$ The authors report that pericardial interstitial cells (PICs) taken from patients with constrictive pericarditis underwent complete division arrest at approximately 14 passages, whereas PICs from patients without pericarditis reached arrest at approximately 25 passages. Senescent cells produced more collagen, attracted more white blood cells, and deposited more calcium. The PICs from patients with pericarditis exhibited senescent changes, including telomere shortening and increased senescence-associated $\beta$-galactosidase (SA$\beta$-gal) activity, a classical marker of cellular senescence. Furthermore, expression of genes involved in extracellular matrix deposition, calcium accumulation, and inflammatory cell recruitment were up-regulated in senescent cells, whereas genes of matrix-degrading enzymes were downregulated. The authors suggest that cellular senescence may contribute to pericardial structural remodeling in idiopathic and post-surgical constrictive pericarditis.

What is the broader relevance of cellular senescence to our routine surgical practice? This question brings us back to yet another fascinating example of evolution in action. Salamanders have a remarkable ability to regenerate damaged complex structures, such as parts of their hearts,

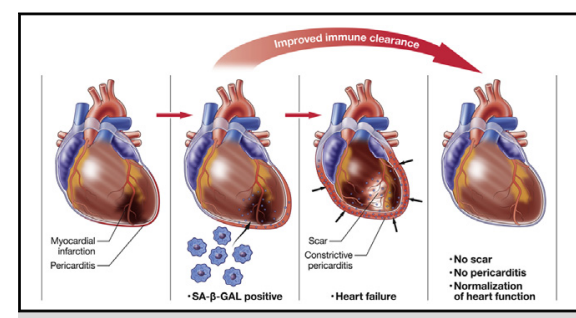

Accumulation of senescent, senescence-associated $\beta$-galactosidase-positive, cells appears to play a key role in the initiation of regeneration processes. Improving immune clearance of senescent cells may result in regeneration of the damaged tissue.

Central Message

Accumulation of senescent cells appears to play a key role in the initiation of regeneration process. Improving immune clearance of senescent cells may result in regeneration of the damaged tissue.

See Article page 966.

brains, eyes, and even amputated limbs. Incredibly, they can do this over and over again, regardless of their age. It was recently demonstrated that salamanders have a superbly efficient mechanism of eliminating senescent cells via macrophage-dependent immune clearance (Figure 1, A). Interestingly, senescent cells are strongly induced during the initial stage of regeneration, but then are completely cleared by the time the damaged organ is regenerated. This phenomenon of induction and clearance of senescent cells appears to be central to the regeneration process. ${ }^{3}$ Furthermore, this process may also play an important role in embryonic tissue development in mammals. ${ }^{4,5}$ Most remarkably, it appears that the mammalian myocardium continues to retain this regenerative capacity even during postnatal development, at least in the neonatal period. ${ }^{6,7}$ Accumulation of senescent cells in mammals appears to be linked to the age-related decline in regenerative capability ${ }^{8}$ and may lead to a number of age-related disorders, ${ }^{9}$ of which constrictive pericarditis may be just one example.

Clearly, the biological significance of cellular senescence goes far beyond constrictive pericarditis. Efficient elimination of senescent cells in humans (Figure 1, $B$ ) may become a promising therapeutic strategy not only in patients with constrictive pericarditis, but also in those with evolving myocardial infarction or with any damage to an organ 


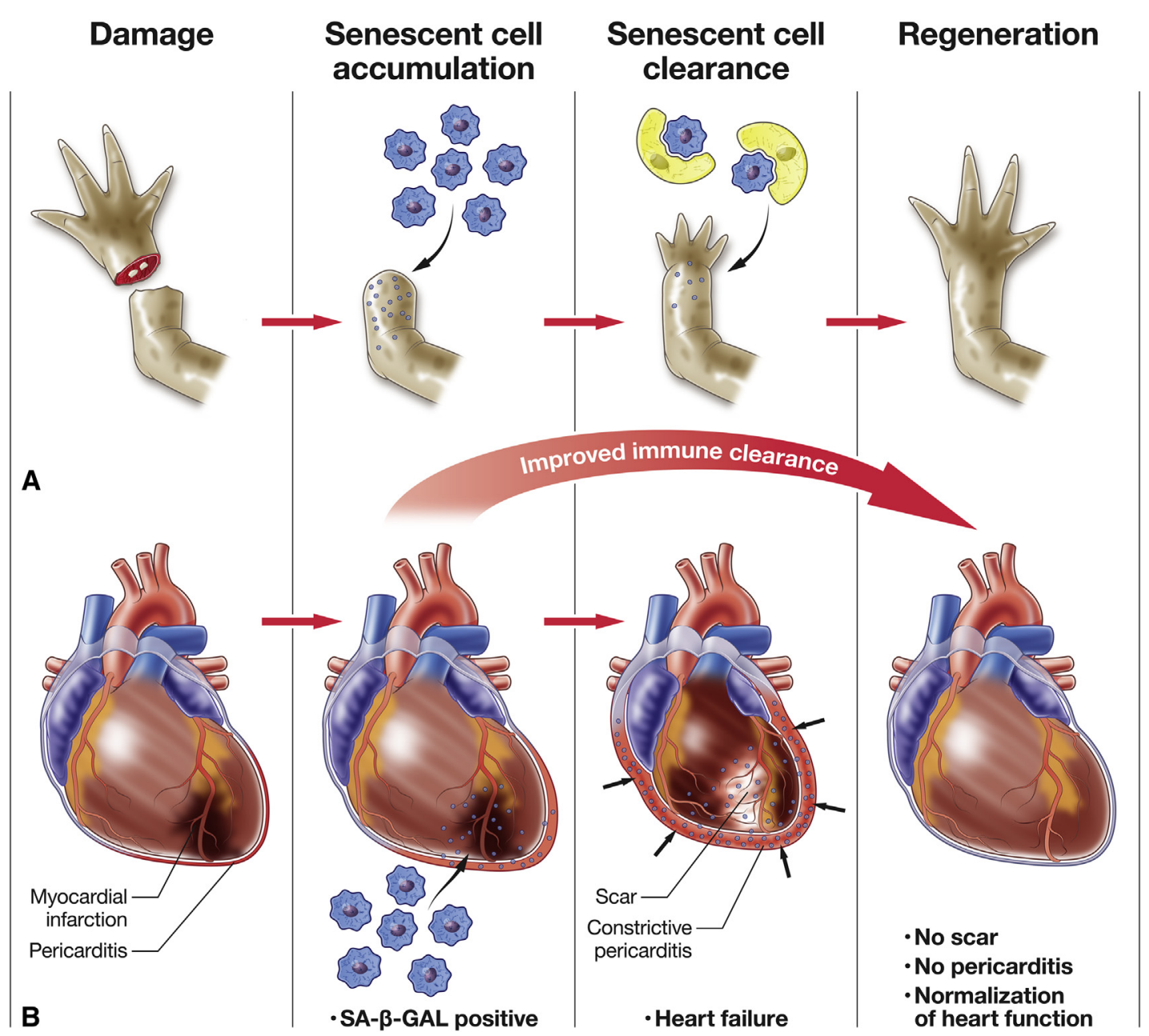

FIGURE 1. Accumulation of senescent, senescence-associated $\beta$-galactosidase-positive, cells appears to play a key role in the initiation of regeneration process. A, In salamanders, senescent cells are efficiently eliminated via macrophage-dependent immune clearance, with complete regeneration of the damaged limb or organ. B, In humans, accumulation of senescent cells after myocardial infarction or pericarditis may result in scar formation and constrictive pericarditis. Improving the immune clearance of senescent cells may result in regeneration of the damaged tissue. SA- $\beta$-GAL, Senescence-associated $\beta$-galactosidase.

with impaired regenerative potential. Could constrictive pericarditis be reversed by effective elimination of senescent cells? Could myocardial function be improved by inducing cellular regeneration after myocardial infarction? Could hypoplastic myocardium be regenerated in congenital heart disease? Will advances in cellular biology revolutionize the surgical management of cardiovascular disorders, or will such interventions remain an elusive holy grail? Time will tell. Whatever the case may be, solid knowledge of cellular biology will be indispensable for the next generation of academic surgeons.

\section{References}

1. Hayflick L, Moorhead PS. The serial cultivation of human diploid cell strains. Exp Cell Res. 1961;25:585-621.

2. Han L, Li X, Zhang G, Xu Z, Gong D, Lu F, et al. Pericardial interstitial cell senescence responsible for pericardial structural remodeling in idiopathic and postsurgical constrictive pericarditis. J Thorac Cardiovasc Surg. 2017;154: 966-75.e4.

3. Yun MH, Davaapil H, Brockes JP. Recurrent turnover of senescent cells during regeneration of a complex structure. eLife. 2015;4.

4. Munoz-Espin D, Canamero M, Maraver A, Gomez-Lopez G, Contreras J, MurilloCuesta S, et al. Programmed cell senescence during mammalian embryonic development. Cell. 2013;155:1104-18.

5. Storer M, Mas A, Robert-Moreno A, Pecoraro M, Ortells MC, Di Giacomo V, et al. Senescence is a developmental mechanism that contributes to embryonic growth and patterning. Cell. 2013;155:1119-30.

6. Porrello ER, Mahmoud AI, Simpson E, Hill JA, Richardson JA, Olson EN, et al. Transient regenerative potential of the neonatal mouse heart. Science. 2011;331: 1078-80.

7. Porrello ER, Mahmoud AI, Simpson E, Johnson BA, Grinsfelder D, Canseco D, et al. Regulation of neonatal and adult mammalian heart regeneration by the miR-15 family. Proc Natl Acad Sci USA. 2013;110:187-92.

8. Sousa-Victor P, Gutarra S, Garcia-Prat L, Rodriguez-Ubreva J, Ortet L, RuizBonilla V, et al. Geriatric muscle stem cells switch reversible quiescence into senescence. Nature. 2014;506:316-21.

9. van Deursen JM. The role of senescent cells in ageing. Nature. 2014;509: $439-46$. 